\title{
STUDY OF THE CASCADED DOUBLY FED INDUCTION MACHINE DYNAMICS UNDER VECTOR CONTROL
}

\author{
Carlos H. S. de Vasconcelos ${ }^{1}$, Antonio C. Ferreira ${ }^{2}$, Richard M. Stephan ${ }^{2}$ \\ ${ }^{1}$ CEFET-MG, Leopoldina - MG, Brasil \\ ${ }^{2}$ COPPE/UFRJ, Rio de Janeiro - RJ, Brasil \\ e-mail: vasconcelos@leopoldina.cefetmg.br, ferreira@coep.ufrj.br, richard@dee.ufrj.br
}

\begin{abstract}
Brushless Doubly-Fed Induction Machines (BDFIM) present many industrial advantages due to the lack of brushes. A foreseen major application is for Wind Power Generation in substitution to the well known and used Doubly-Fed Induction Generator. The Cascaded Doubly Fed Induction Generator (CDFIG), composed of two Doubly-Fed Induction Machines (DFIM), can be used as starting point to the study of BDFIM and is the object of the present paper. The dynamic model and vector control of the CDFIG will be discussed. The reference frame is given by the stator flux of the power machine. The proposed control has a cascaded structure, with internal current loop and two different possibilities of external control loop: speed control or power control. In both cases the reference is given by a Maximum Power Point Tracking (MPPT) scheme and the reactive power reference is established in accordance with the requirements of reactive power compensation. Experimental results are presented to validate the proposed methodology.
\end{abstract}

Keywords - Brushless Doubly Fed Machine, Cascaded Doubly Fed Induction Machine, Wind Power Generator.

\section{NOMENCLATURE}

$\begin{array}{ll}\text { A. Variables } & \\ u & \text { Voltage. } \\ i & \text { Current. } \\ \psi & \text { Flux linkage. } \\ R & \text { Resistance. } \\ L & \text { Linkage inductance. } \\ M & \text { Mutual inductance. } \\ \omega & \text { Angular velocity. } \\ P & \text { Number of pole pairs. } \\ m & \text { Electromagnetic torque. }\end{array}$

$\begin{array}{ll}\text { B. Subscripts } & \text { and Superscripts } \\ g & \text { General reference frame. } \\ e & \text { Excitation reference frame. } \\ p & \text { Power Machine. } \\ c & \text { Control Machine. } \\ s & \text { Stator. } \\ r & \text { Rotor. } \\ L & \text { load. } \\ s m & \text { Synchronous speed. }\end{array}$

Manuscript received 23/03/2017; first revision 15/05/2017; accepted for publication 27/06/2017, by recommendation of Editor Marcelo Cabral Cavalcanti.

\author{
ep $\quad$ Electrical speed of Power Machine. \\ epc Electrical speed between Power and Control \\ Machine.
}

\section{INTRODUCTION}

The brushless doubly-fed machine presents several advantages when used in adjustable speed drive or as a wind turbine generator. The absence of slip rings and brushes increase the lifetime of the machine and reduces the maintenance costs [1]. Recent publications show three common types of brushless doubly-fed machine: Brushless doubly-fed machine (BDFM), single frame cascaded doublyfed induction machine (SF-CDFIM) and cascaded doubly-fed induction machine (CDFIM) [2].

The first one is the most compact machine. It consists in two three-phase winding systems in the same frame and mounted in the same slots. The rotor structure in nested-loop was proposed by Broadway and Burbridge [3]. The second type is composed of two sets of stator winding assembled next to each other in the same frame and there are two individual rotor arranged on the shaft. Both machines types hold a prototype status and are not standard manufacturing [4].

The third one will be studied in this paper. It consists in the connection of two DFIM, both mechanically and electrically and can have a higher commercial appeal since DFIMs are of standard manufacturing. The first motor is called Power Machine and is directly connected to the power system grid while the second one, called Control Machine, is supplied from a power electronic converter. This machine contains slip rings and brushes but, due to the mechanical connection, both rotors have the same rotational speed and the brushes are no longer necessary. The main use of these machines seems to be as generator in wind power plants, with variable speed operation [5], [6].

The fundamental concepts to understand the operation in steady state of CDFIM were shown in a previous paper. Based on these considerations, the possible points of operation and the power flow of the set were deduced [7].

The present paper aims the study of the dynamic characteristics of the CDFIM under vector control based on the orientation on the Power Machine stator flux. This control approach can be divided in three parts: Current control loop, speed control loop and power control loop. Based on the experimental result of current control loop, the transient response of the CDFIM to current step changes in the Control Machine and the cross coupling disturbance are examined. In the speed control loop and the power control loop, the decoupling of the active and reactive power is examined. The 
main contribution of this work is to verify the speed and power control loop dynamic characteristics and validate the vector control based on the orientation on the Power Machine stator flux strategies applied to a CDFIM.

\section{CDFIM MODEL}

The model of the CDFIM can be derived from the model of the DFIM. Considering a symmetric three-phase winding and a sinusoidal magnetic flux density and disregarding magnetic saturation and the temperature effects, the DFIM model can be supposed linear. The model of DFIM in a general reference frame (" $g$ ") is given by:

$$
\begin{gathered}
\bar{u}_{s}^{g}=R_{s} \bar{i}_{s}^{g}+\frac{d \bar{\psi}_{s}^{g}}{d t}+j \omega^{g} \bar{\psi}_{s}^{g} \\
\bar{u}_{r}^{g}=R_{r} \bar{i}_{r}^{g}+\frac{d \bar{\psi}_{r}^{g}}{d t}+j\left(\omega^{g}-\omega_{r}\right) \bar{\psi}_{r}^{g} \\
\bar{\psi}_{s}^{g}=L_{s} \bar{i}_{s}^{g}+M \bar{i}_{r}^{g} \\
\bar{\psi}_{r}^{g}=M \bar{i}_{s}^{g}+L_{r} \bar{i}_{r}^{g}
\end{gathered}
$$

and the mechanical equation of the DFIM can be written as follow:

$$
m(t)-m_{L}(t)=J \frac{d \omega_{m}}{d t}+B \omega_{m}
$$

The electromagnetic torque of the DFIM is given by:

$$
m=-\frac{3}{2} P \frac{M}{L_{s}}\left(\bar{\psi}_{s}^{g} \times \bar{i}_{r}^{g}\right)=-\frac{3}{2} P M\left(\bar{i}_{s}^{g} \times \bar{i}_{r}^{g}\right) .
$$

The CDFIM is composed of the union of two DFIMs in back-to-back configuration, where the rotors are connected electrically and mechanically. The CDFIM is shown in Figure 1 .

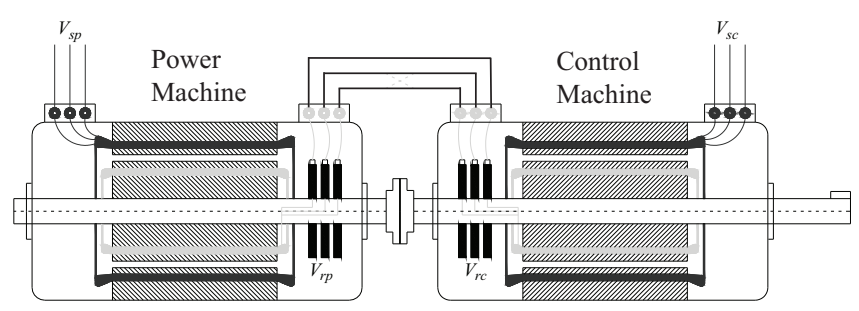

Fig. 1. CDFIM: two DFIM connected back-to-back.

Considering the rotor connection in positive phase sequence and the arrangement of the machines in back-toback, the electric quantities of the rotor are in opposition to the relative speed of the rotor. The individual rotor phase voltages and currents are shown in Figure 2.

The rotor parameters assume the relationship:

$$
\begin{aligned}
& R_{r}=R_{r p}+R_{r c} ; \\
& L_{r}=L_{r p}+L_{r c} \\
& \bar{u}_{r}^{g}=\bar{u}_{r p}^{g}=\bar{u}_{r c}^{g} ; \\
& \bar{i}_{r}^{g}=\bar{i}_{r p}^{g}=-\bar{i}_{r c}^{g} \text {. }
\end{aligned}
$$

The rotor connected in positive phase sequence makes the individual torque components operate in the same direction,

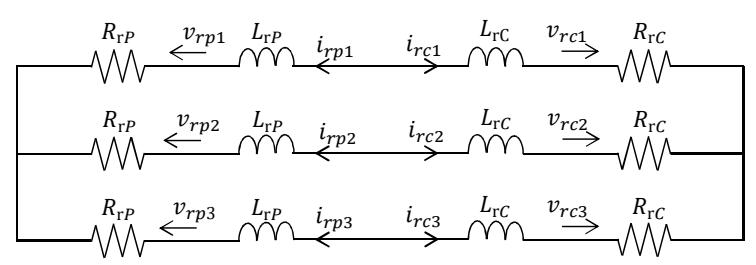

Fig. 2. CDFIM: positive phase sequence rotor connection.

but with the negative phase connection the individual torque components work in opposite direction. The negative sequence phase connection does not have real use in industrial applications [8].

The CDFIM dynamic model can be written in a general reference frame (" $g$ "). To describe this model, it is necessary to move all space vectors from their own reference frame to a general one. The reference frame for the Power Machine is stationary and the reference frame for the Control Machine is moving in positive direction relative to Power Machine frame with the mechanical rotor speed $\left(\omega_{e p}\right)$ in electrical radians por second. The reference frame system of CDFIM is shown in Figure 3 [9], where $\omega_{e p c}=\left(P_{p}+P_{c}\right) \omega_{r}$ and $\omega_{e p}=P_{p} \omega_{r}$.

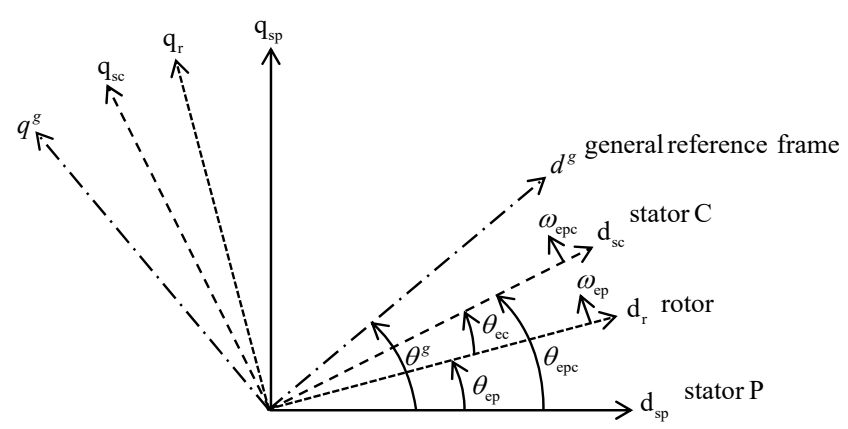

Fig. 3. CDFIM: reference frame and angles.

Considering a general reference frame, the CDFIM model is given by [10], [11]:

$$
\begin{gathered}
\bar{u}_{s p}^{g}=R_{s p} \bar{i}_{s p}^{g}+\frac{d \bar{\psi}_{s p}^{g}}{d t}+j \omega^{g} \bar{\psi}_{s p}^{g} \\
\bar{u}_{r}^{g}=R_{r} \bar{i}_{r}^{g}+\frac{d \bar{\psi}_{r}^{g}}{d t}+j\left(\omega^{g}-\omega_{e p}\right) \bar{\psi}_{r}^{g} \\
\bar{u}_{s c}^{g}=R_{s c} \bar{i}_{s c}^{g}+\frac{d \bar{\psi}_{s c}^{g}}{d t}+j\left(\omega^{g}-\omega_{e p c}\right) \bar{\psi}_{s c}^{g} .
\end{gathered}
$$

The flux linkages in a general reference frame can be expressed as:

$$
\begin{gathered}
\bar{\psi}_{s p}^{g}=L_{s p} \bar{i}_{s p}^{g}+M_{p} \bar{i}_{r}^{g} \\
\bar{\psi}_{r}^{g}=M_{p} \bar{i}_{s p}^{g}+L_{r} \bar{i}_{r}^{g}-M_{c} \bar{i}_{s c}^{g} \\
\bar{\psi}_{s c}^{g}=L_{s c} \bar{i}_{s c}^{g}-M_{c} \bar{i}_{r}^{g} .
\end{gathered}
$$

The total eletromagnetic torque in the CDFIM shaft produced by both machines is calculated from

$$
m_{e p c}=m_{e p}-m_{e c} .
$$


Because of the back-to-back connection, the $m_{e c}$ signal is in opposition of the $m_{e p}$, resulting in a sum of the both torque.

The electromagnetic torque, invariant with the reference frame, is given by [12]:

$$
m_{e p c}=-\frac{3}{2}\left[\left(P_{p} M_{p} \bar{i}_{s p}^{g}+P_{c} M_{c} \bar{i}_{s c}^{g}\right) \times \bar{i}_{r}^{g}\right]
$$

and the mechanical equation of the CDFIM can be written as follows:

$$
m_{e p c}(t)-m_{L}(t)=J \frac{d \omega_{m}}{d t}+B \omega_{m}
$$

and

$$
\frac{d \theta_{m}}{d t}=\omega_{m}
$$

The steady state speed of the CDFIM expressed in function of the Power Machine frequency $\left(f_{p}\right)$ and the Control Machine frequency $\left(f_{c}\right)$ is given by:

$$
\omega_{m}=\frac{2 \pi\left(f_{p}+f_{c}\right)}{P_{p}+P_{c}}
$$

and the synchronous (natural) speed of the CDFIM is obtained when the Control Machine frequency is set at zero $\left(f_{c}=0\right)$ and is given by:

$$
\omega_{s m}=\frac{2 \pi\left(f_{p}\right)}{P_{p}+P_{c}} .
$$

\section{STATOR FLUX ORIENTED CONTROL}

The torque of the CDFIM (15) expressed in function of the Power Machine flux and the Control Machine stator current (6) can be written in the general reference frame as:

$$
m_{e p c}=-\frac{3}{2}\left[\left(P_{p} \frac{M_{p}}{L_{s p}} \bar{\psi}_{s p}^{g}+P_{c} M_{c} \bar{i}_{s c}^{g}\right) \times \bar{i}_{r}^{g}\right] .
$$

This equation shows that the torque control is directly related with the Power Machine flux and the Control Machine stator current. By imposing the d-component of the Power Machine stator flux as the reference frame for the CDFIM vector control, it follows $\psi_{q s p}^{e}=0, \psi_{d s p}^{e}=\psi_{s p}^{e}$, where the superscript "e" indicates the excitation reference frame of the Power Machine direct flux. The reference frame for the CDFIM in Power Machine stator flux control is depicted in Figure 4.

Isolating the rotor current in (11) and substituting in (12), one obtains:

$$
\bar{\psi}_{r}^{e}=\left(M_{p}-\frac{L_{r} L_{s p}}{M_{p}}\right) \bar{i}_{s p}^{e}+\frac{L_{r}}{M_{p}} \bar{\psi}_{s p}^{e}-M_{c} \bar{i}_{s c}^{e} .
$$

Isolating the Power Machine stator current in (21) and replacing it in (8), one obtains the model for the CDFIM in stator flux orientation [13]:

$$
\frac{d \psi_{d s p}^{e}}{d t}-\frac{R_{s p} L_{r}}{K M_{p}} \psi_{d s p}^{e}=-\frac{R_{s p}}{K} \psi_{d r}^{e}-\frac{R_{s p} M_{c}}{K} i_{d s c}^{e}+u_{d s p}
$$

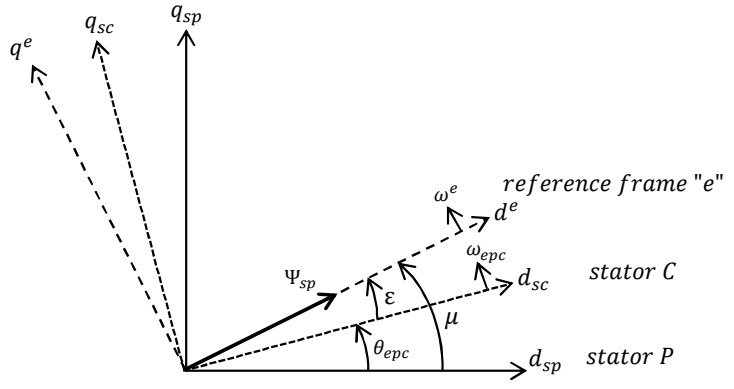

Fig. 4. Reference frame for the CDFIM with Power Machine stator flux control.

$$
\frac{d \mu}{d t}=\omega^{e}=-\frac{R_{s p}}{K} \frac{\psi_{q r}^{e}}{\psi_{d s p}^{e}}-\frac{R_{s p} M_{c}}{K} \frac{i_{q s c}^{e}}{\psi_{d s p}^{e}}+\frac{u_{q s p}^{e}}{\psi_{d s p}^{e}}
$$

with $K$ given by:

$$
K=M_{p}-\frac{L_{r} L_{s p}}{M_{p}} .
$$

\section{A. Current Control Loop}

Rewriting (11) to (13), the Control Machine flux can be express in function of the rotor flux, Power Machine flux and Control Machine current as:

$$
\bar{\psi}_{s c}^{e}=-\frac{M_{c}}{K_{a}} \bar{\psi}_{r}^{e}+\frac{M_{p} M_{c}}{K_{a} L_{s p}} \bar{\psi}_{s p}^{e}+K_{b} \bar{i}_{s c}^{e}
$$

with:

$$
K_{a}=L_{r}-\frac{M_{p}^{2}}{L_{s p}} \quad K_{b}=L_{s c}-\frac{M_{c}^{2}}{K_{a}} .
$$

Replacing (25) in the Control Machine voltage (10) in the vector control reference frame and considering only steady state in $d q$-components gives:

$$
\begin{aligned}
u_{d s c}^{e}= & R_{s c} i_{d s c}^{e}+\left(\omega^{e}-\omega_{e p c}\right)\left(\frac{M_{c}}{K_{a}} \psi_{q r}^{e}-K_{b} i_{q s c}^{e}\right) \\
u_{q s c}^{e}= & R_{s c} i_{q s c}^{e}-\left(\omega^{e}-\omega_{e p c}\right)\left(\frac{M_{c}}{K_{a}} \psi_{d r}^{e}-K_{b} i_{d s c}^{e}\right) \\
& +\left(\omega^{e}-\omega_{e p c}\right) \frac{M_{p} M_{c}}{K_{a} L_{s c}} \psi_{s p}^{e} .
\end{aligned}
$$

These equations show two terms of cross coupling, the second term constitute smooth cross coupling in the Control Machine voltage and the third term is a slip proportional term. Only the third term should be include to ensure decoupled control, by increasing steady state accuracy. The feedforward term of $\mathrm{q}$ axis is given by:

$$
\text { feedforward }=\left(\omega^{e}-\omega_{e p c}\right) \frac{M_{p} M_{c}}{K_{a} L_{s c}} \psi_{s p}^{e} .
$$

The current control loop block diagram is shown in Figure 5. The block " $\mu$ " calculates the angle between the stationary reference of stator flux and the excitation reference of Power 


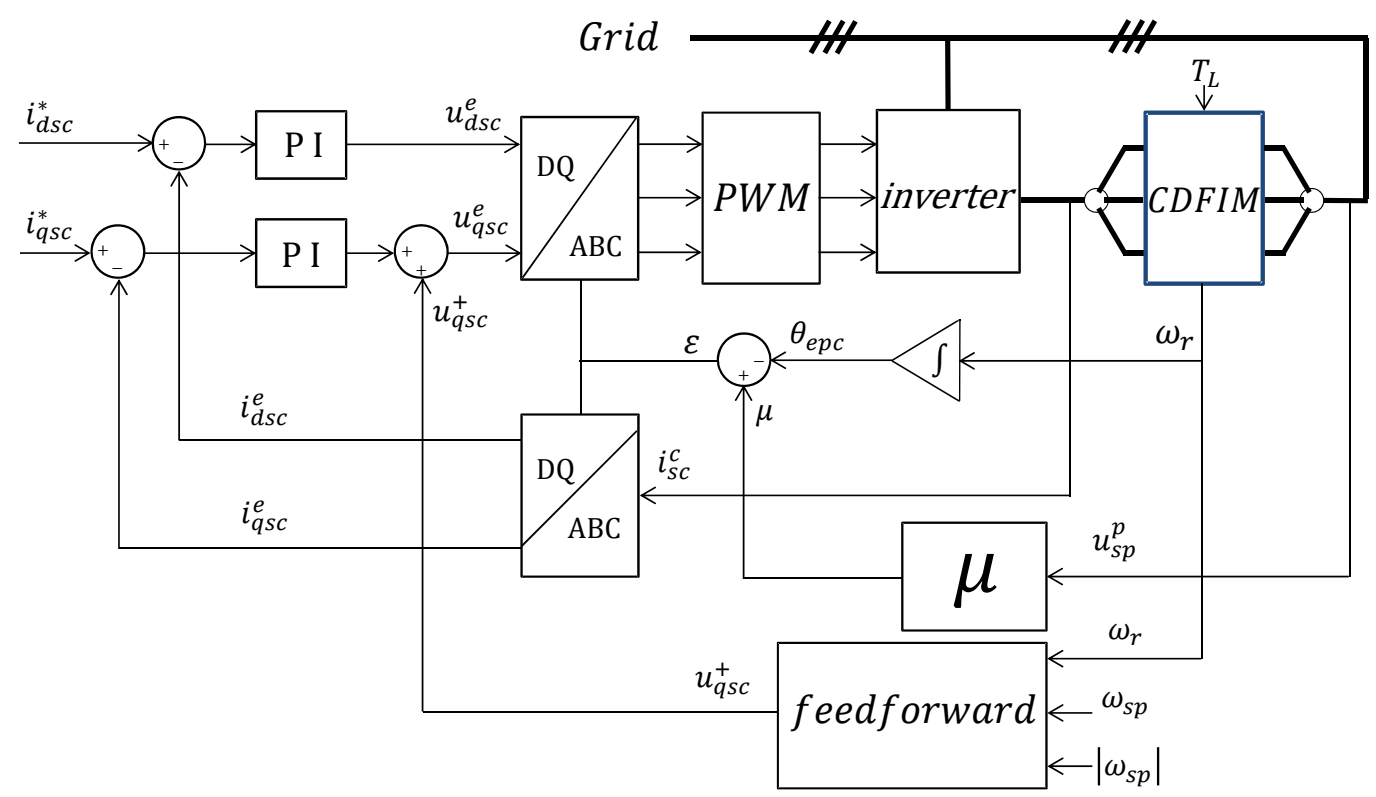

Fig. 5. CDFIM: current control loop with orientation on the Power Machine stator flux.

Machine.

\section{B. Speed Control Loop}

Equation (20) shows that the Control Machine current is directly proportional to the torque. By adding a speed control loop in cascade with the q-component of current control loop one can control the speed of CDFIM.

Rewriting (11) to (13), the rotor current can be expressed as a function of the rotor flux, Power Machine flux and Control Machine current as:

$$
\bar{i}_{r}=\frac{1}{K_{a}} \bar{\psi}_{r}^{e}-\frac{M_{p}}{K_{a} L_{s p}} \bar{\psi}_{s p}^{e}+\frac{M_{c}}{K_{a}} \bar{i}_{s c}^{e} .
$$

Replacing the rotor current in (15), the torque is given by:

$$
\begin{aligned}
m_{e p c}= & \frac{-3}{2}\left[\left(\frac{P_{p} M_{p}}{K_{a} L_{s p}} \bar{\psi}_{s p}^{e}+\frac{P_{c} M_{c}}{K_{a}} \bar{i}_{d s c}^{e}\right) \psi_{q r}^{e}\right. \\
& \left.+\left(\left(P_{p}+P_{C}\right) K_{c} \bar{\psi}_{s p}^{e}-\frac{P_{p} M_{p}}{K_{a}} \bar{\psi}_{d r}^{e}\right) i_{q s c}^{e}\right]
\end{aligned}
$$

with:

$$
K_{c}=\frac{M_{p} M_{c}}{K_{a} L_{s p}}
$$

This equation shows that both components of Control Machine current appear indicating a coupling in the torque control. Analyzing the results of the current control loop simulations, it was observed that the influence of the dcomponent of the current is insignificant when compared with the q-component. Considering the d-component of the Control Machine current constant, the first term of (31) remains constant uncoupling the speed control. The speed control loop of CDFIM is show in Figure 6.

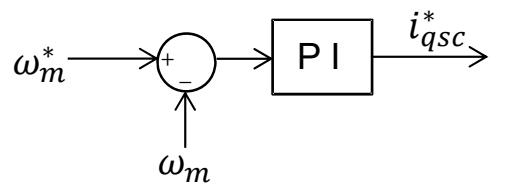

Fig. 6. CDFIM: speed control loop with orientation on the Power Machine stator flux.

\section{Power Control Loop}

The active and reactive power of the Power Machine are calculated as follows:

$$
\begin{aligned}
P_{s p} & =\frac{3}{2}\left(u_{d s p}^{g} i_{d s p}^{g}+u_{q s p}^{g} i_{q s p}^{g}\right) \\
Q_{s p} & =\frac{3}{2}\left(u_{d s p}^{g} i_{q s p}^{g}-u_{q s p}^{g} i_{d s p}^{g}\right) .
\end{aligned}
$$

Manipulating (21), the relationship between the Power Machine and the Control Machine currents in $d q$ components are given by:

$$
\begin{gathered}
i_{d s p}^{e}=\frac{1}{K} \psi_{d r}^{e}-\frac{L_{r}}{K M_{p}} \psi_{s p}^{e}+\frac{M_{c}}{K} i_{d s c}^{e} \\
i_{q s p}^{e}=\frac{1}{K} \psi_{q r}^{e}+\frac{M_{c}}{K} i_{q s c}^{e} .
\end{gathered}
$$

Considering the stator resistance small in comparison with the stator reactance $\left(R_{s p} \ll \omega_{s p} L_{s p}\right)$, it follows:

$$
\bar{u}_{s p} \approx \frac{d \bar{\psi}_{s p}}{d t}
$$

This equation shows that the Power Machine stator voltage has the same angular frequency as the Power Machine stator flux ( $\omega_{s p}=\omega^{e}=$ constant ). The magnitude of the Power Machine stator flux is calculated as follow: 


$$
\psi_{s p} \approx \frac{\sqrt{2} u_{s p}}{\omega_{s p}} .
$$

Substituting (35), (36) and (38) in (33) and (34), it follows:

$$
\begin{gathered}
P_{s p}=\frac{3}{2} \sqrt{2} u_{s p}\left(\frac{1}{K} \psi_{q r}^{e}+\frac{M_{c}}{K} i_{q s c}^{e}\right) \\
Q_{s p}=\frac{3}{2} \sqrt{2} u_{s p}\left(\frac{1}{K} \psi_{d r}^{e}-\frac{L_{r}}{K M_{P}} \psi_{s p}^{e}+\frac{M_{c}}{K} i_{d s c}^{e}\right) .
\end{gathered}
$$

These equations show the cross coupling in the power control. The rotor flux term $\left(\bar{\psi}_{r}^{g}=\left(R_{r} / j\left(\omega^{g}-\omega_{e p}\right)\right) \bar{i}_{r}^{g}\right)$ can cause cross coupling and its intensity depends on the rotor resistance and speed. Disregarding the cross coupling, the qcomponent of the Control Machine current controls the active power of the Power Machine and d-component controls the reactive power.

By adding a power control loop in cascade with the current control loop one can control the power flow of CDFIM. The Power control scheme of CDFIM flux oriented control is shown in Figure 7. The block "Power Calculation" utilizes (33) and (34) to calculate the active and reactive power.

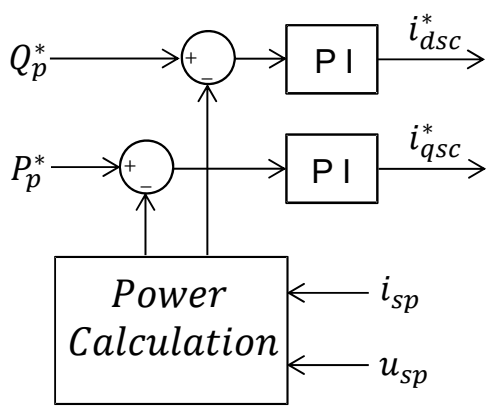

Fig. 7. CDFIM: power control loop.

\section{MPPT TECHNIQUE}

The MPPT techniques determines the operation of the generator to obtain maximum energy from wind. The maximum power extraction algorithms can be classified in the two more common control methods, namely tip speed ratio (TSR) control and power signal feedback (PSF) control [14].

The power produced by a wind turbine is given by:

$$
P_{0}=\frac{1}{2} \rho A C_{p}(\lambda, \beta) v_{v}^{3}
$$

where $\rho$ is the air density, $A$ is the area swept by the rotor blades, $C_{p}$ is the power coefficient, $v_{v}$ is the wind speed. The power coefficient is a function of tip speed ratio $(\lambda)$ and pitch angle $(\beta)$. The tip speed ratio is defined as:

$$
\lambda=\frac{\omega_{r} R}{v_{v}}
$$

where $\omega_{r}$ is the turbine angular speed and $R$ is the radius of the area swept by the rotor blades in meters. The power coefficient is determined by the aerodynamic design.
To extract the maximum possible power, the turbine should operate at optimum tip speed ratio $\lambda_{\text {opt }}$. The turbine mechanical power can be represented as a function of rotor speed for various wind speeds. Figure 8 shows the turbine power as a function of rotor speed at various wind speeds and the maximum power trajectory [15].

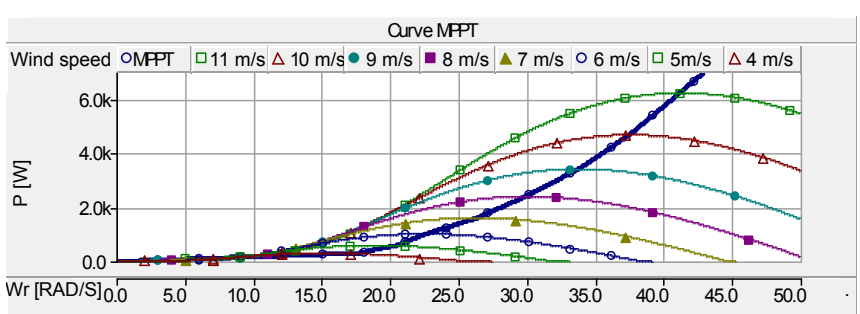

Fig. 8. Wind turbine maximum power trajectory.

\section{A. MPPT-TSR}

This method adjusts the rotational speed of the turbine in order to extract the maximum power. This method uses the measurement of wind speed and turbine speed and the knowledge of optimum tip speed ratio to extract maximum power of the wind.

The optimal rotor speed in function of wind speed is given by:

$$
\omega_{r_{o p t}}=\frac{\lambda_{\text {opt }} v_{v}}{R} .
$$

The block diagram of MPPT-TSR control loop is shown in Figure 9. Where $\omega_{r}^{*}$ is the reference of rotor speed for the speed control loop.

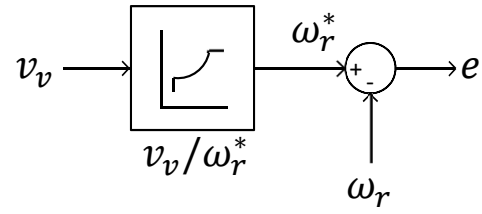

Fig. 9. Block diagram of the MPPT-TSR.

\section{B. MPPT-PSF}

To apply this method it is required to have the knowledge of the MPPT curve of the wind turbine. This method uses the measurement of generator speed and the active power of CDFIM to extract maximum power of the wind.

Neglecting the rotor converter losses, the active power of CDFIG is given by:

$$
P_{a}^{*}=P_{g}+P_{p a}=P_{g}+P_{s p}+P_{s c}+P_{r o t}
$$

where $P_{a}^{*}$ is the reference power to be generated, $P_{g}$ the total generated power, $P_{p a}=P_{s p}+P_{s c}+P_{r o t}$, with $P_{p a}, P_{s p}, P_{s c}$, $P_{r o t}$ the total losses, the stator Power Machine and the stator Control Machine losses and the rotational losses, respectively. In Figure 10 the block diagram of the MPPT-PSF control loop is shown. $P_{P}^{*}$ is the reference of active power for the power control loop. 


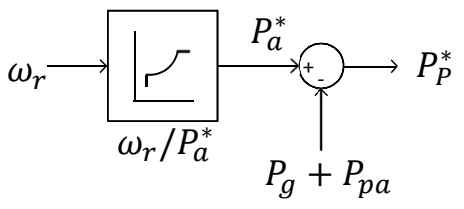

Fig. 10. Block diagram of the MPPT-PSF.

\section{EXPERIMENTAL IMPLEMENTATION}

To validate the performance of the vector control of the CDFIM with stator flux orientation, tests have been carried out in a test bench using the CDFIM. The experimental test bench is shown in Figure 11. The references of Speed control (TSR) and Power control (PSF) are generated by the MPPT techniques.

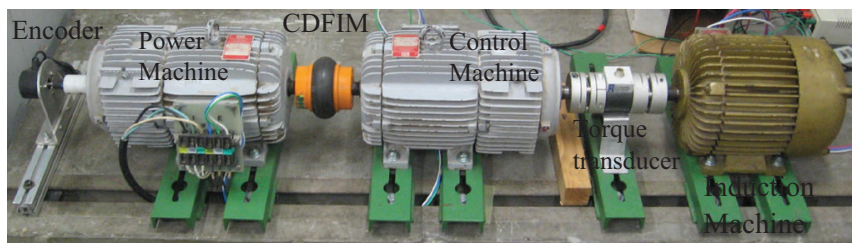

Fig. 11. CDFIM test bench (left to right): encoder, CDFIM (Power Machine and Control Machine), torque transducer and induction machine (IM) to simulate the wind.

The vector control and PWM $(8 \mathrm{kHz})$ are implemented on a DSP-TMS320F28335, Texas Instruments. The measurement equipment are composed of four current sensors (LEM LA55P), five voltage sensors (LEM LV20-P), incremental optical encoder and the torque transducer (HB T22). The Power Machine is directly connected to the grid $(220 \mathrm{~V}, 60 \mathrm{~Hz})$ and the Control Machine is supplied by a back-to-back converter. The IM is powered by PWM inverter with constant $V / f$ control.

The Power Machine and the Control Machine are composed of two identical wound rotor induction machines. The induction machines parameters are given in Table I.

TABLE I

CDFIM: Power and Control Machine Parameters

\begin{tabular}{cccc}
\hline Parameter & Value & Parameter & Value \\
\hline Power & $3 \mathrm{HP}$ & $R_{s}$ & $0.861 \Omega$ \\
\hline speed & $178 \mathrm{rad} / \mathrm{s}$ & $R_{r}$ & $0.963 \Omega$ \\
\hline Voltage & $220 \mathrm{~V}$ & $L_{s}$ & $4.631 \mathrm{mH}$ \\
\hline pole pair & 2 & $L_{r}$ & $4.631 \mathrm{mH}$ \\
\hline stator current & $10.9 \mathrm{~A}$ & $M$ & $73.049 \mathrm{mH}$ \\
\hline Rotor current & $13.4 \mathrm{~A}$ & $J$ & $0.02 \mathrm{~kg} . \mathrm{m}^{2}$ \\
\hline
\end{tabular}

This section presents three experimental results of vector control of the CDFIM: current control loop, speed control loop and power control loop. To reduce the rating of the converter connected to the Control Machine, it is expected that the CDFIM will operate at a limited speed range around its natural synchronous speed, which is $94,25 \mathrm{rad} / \mathrm{s}$ for the experimental setup. The speed settings used in the tests were chosen to have the machine working above its natural speed as in this case power is extracted from both machines, and the values were randomly chosen.

\section{A. Current Control Loop}

In this experiment the CDFIM was started with a reference speed equal to $110 \mathrm{rad} / \mathrm{s}$. A variation in the q-component of the Control Machine current from 1.0 A to -3.0 A was imposed and back to $1.0 \mathrm{~A}$, while the d-component was left at a constant value of $2.0 \mathrm{~A}$. Figure 12 shows the results for the current control loop. It can be seen the light cross coupling in the d-component.

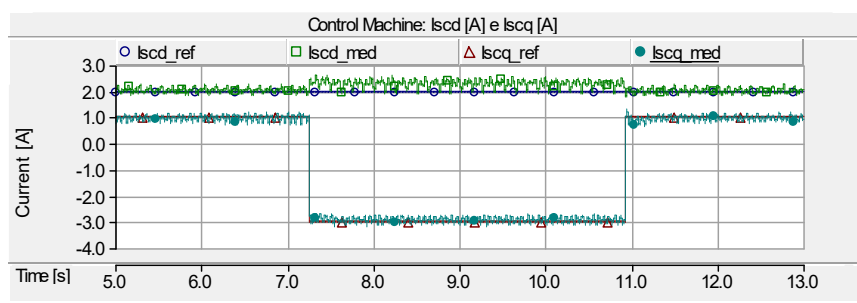

Fig. 12. CDFIM - Current control loop: Control Machine currents.

Figure 13 shows the Power Machine active power. It can be seen that when a variation in q-component of the Control Machine current was imposed, the active power of Power Machine was altered. This behavior shows that the active power of Power Machine can be controlled by the qcomponent of Control Machine current.

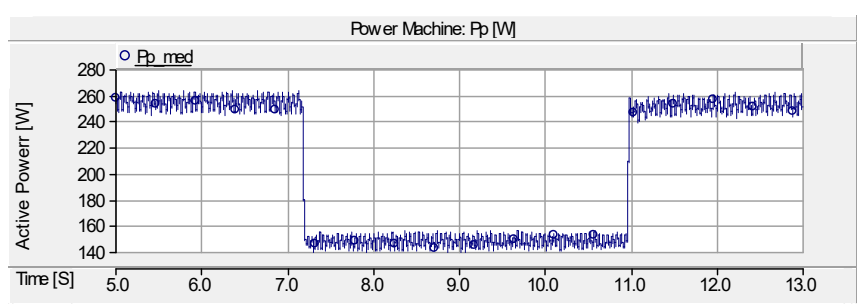

Fig. 13. CDFIM - Current control loop: Power Machine active power.

\section{B. Speed Control Loop}

In this experiment the CDFIM was started with a reference speed equal to $110 \mathrm{rad} / \mathrm{s}$. The d-component of Control Machine current was left at a constant value of $1.0 \mathrm{~A}$. After 3.5 seconds a variation in torque in the mechanical power source was introduced. Figure 14 shows the results for the mechanical speed of the CDFIM. It can be seen that with the variation of load applied to the axis of CDFIM, the speed control maintains constant speed.

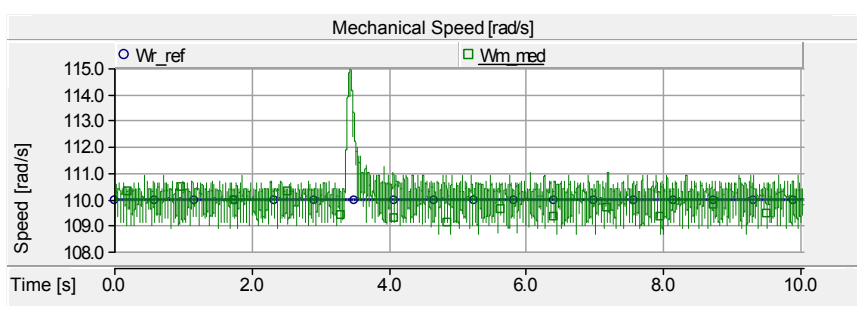

Fig. 14. CDFIM - Speed control loop: mechanical speed (110 rad/s).

It can be seen in Figure 15 the transient response of the Control Machine current and the light cross coupling in the q-component.

Figure 16 shows the active and reactive power of the Power Machine. It can be seen that when a variation in torque was imposed, the active power flow in the Control Machine is on 


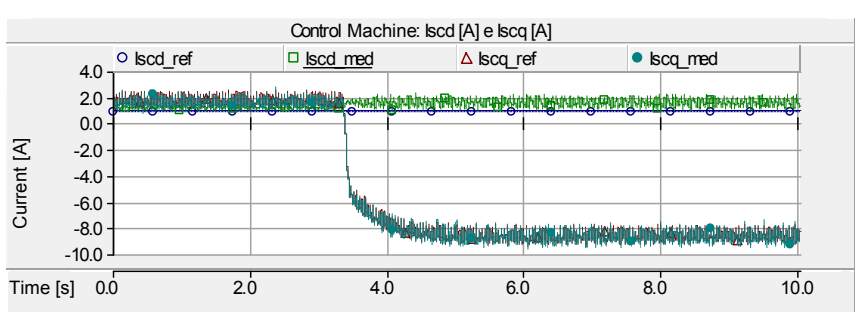

Fig. 15. CDFIM - Speed control loop: Control Machine currents.

the order of $15 \%$ in relation to the Power Machine. This behavior shows that the speed of the CDFIM can be controlled by the q-component of the Control Machine current.

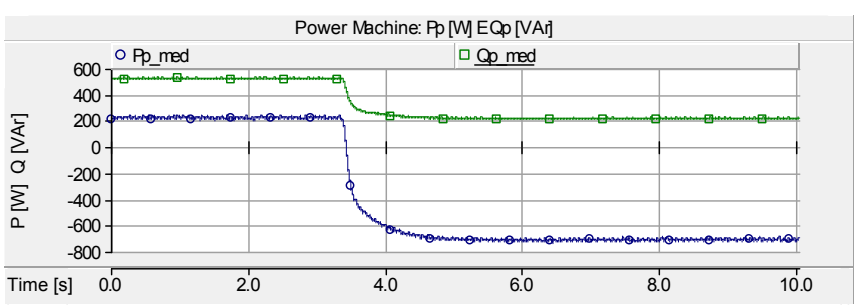

Fig. 16. CDFIM - Speed control loop: Power Machine active and reactive power.

\section{Power Control Loop}

In this experiment the CDFIM was started with a reference speed equal to $116 \mathrm{rad} / \mathrm{s}$ and the reference signal of the active power of the Power Machine is set in $-150 \mathrm{~W}$, while the reactive power of the Power Machine is set in 150 var. During the interval from 5.3 seconds to 9.2 seconds a variation in reference active power to $450 \mathrm{~W}$ was introduced. Figure 17 shows the active and reactive powers of the Power Machine. It can be seen that the active and reactive power control are uncoupled. This result also shows that the machine can work as motor (positive power) or generator (negative power).

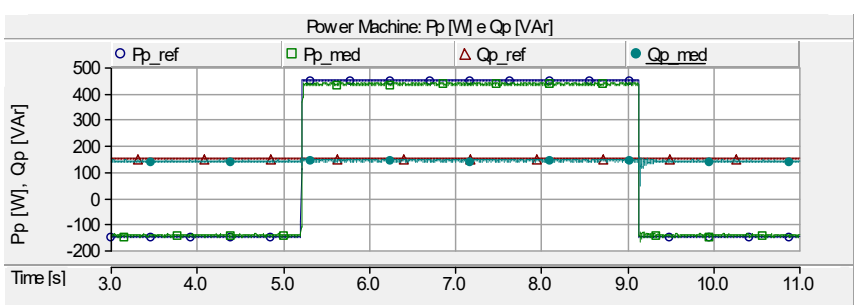

Fig. 17. CDFIM - Power control loop: Power Machine active and reactive power.

The dynamic performance of the Control Machine currents are shown in Figure 18. It can be seen that a variation in the reference active power acts directly in the q-component of Control Machine current. It can also be seen that this speed variation causes a small change in the d-component of the Control Machine current to keep the reactive power constant.

It can also be seen that this speed variation causes a small change in the d-component of the Control Machine current to keep the reactive power constant.

Figure 19 shows the mechanical speed of the CDFIM. It can be seen, that due to the variation of the active power reference, the mechanical speed of CDFIM was adjusted to a new speed.

This result also shows that the machine can work as motor (positive power) or generator (negative power).

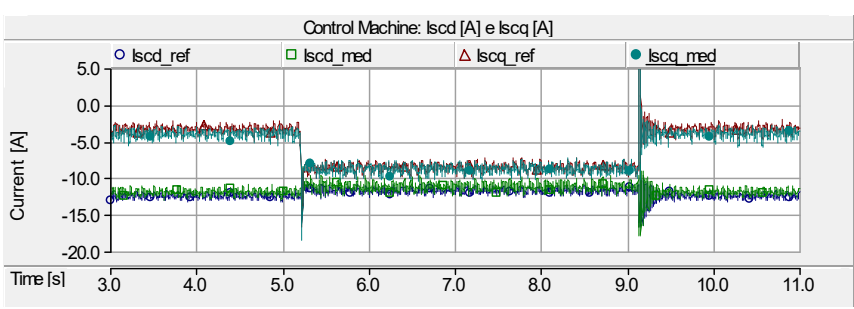

Fig. 18. CDFIM - Power control loop: Control Machine currents.

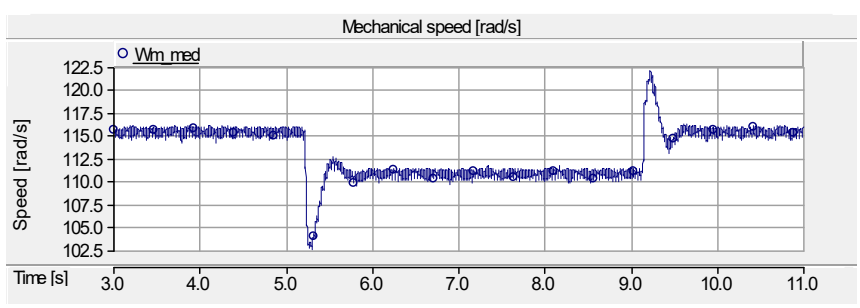

Fig. 19. CDFIM - Power control loop: mechanical speed (116 rad/s).

\section{CONCLUSION}

This paper presents a study of the cacaded doubly-fed induction machine dynamics under vector control. The fundamental concepts to understand CDFIM model and stator flux oriented control are shown.

The experimental results present a good dynamic response and proved the theoretical studies. The cross coupling intensity presented in the control loops depends on the rotor speed and rotor resistance. The cross coupling in the speed control can be neglected. The power control loop is efficient to manipulate directly the active and reactive powers.

The CDFIM associated to the vector control based on Power Machine stator flux proved to be a good option to control the speed and power flow in variable speed drives.

\section{ACKNOWLEDGEMENTS}

This work was supported in part by CAPES, CNPq, BNDES and FAPERJ.

\section{REFERENCES}

[1] I. Gowaid, A. Abdel-Khalik, A. Massoud, S. Ahmed, "Ride-Through Capability of Grid-Connected Brushless Cascade DFIG Wind Turbines in Faulty Grid Conditions - A Comparative Study", IEEE Transactions on Sustainable Energy, vol. 4, no. 4, pp. 1002-1015, Oct 2013.

[2] H. Gorginpour, H. Oraee, R. A. McMahon, "Performance Description of Brushless DoublyFed Induction Machine in Its Asynchronous and Variable Speed Synchronous Modes", Journal of Electromagnetic Analysis and Applications, vol. 3, no. 12, pp. 490-511, Dec 2011.

[3] A. Broadway, L. Burbridge, "Self-cascaded machine: a low-speed motor or high-frequency brushless alternator", Proceedings of the Institution of Electrical Engineers, vol. 117, no. 7, pp. 1277 -1290, July 1970.

[4] P. Löhdefink, A. Dietz, A. Möckel, "Modeling and power flow analysis of cascaded doubly-fed 
induction machines", in 5th International Electric Drives Production Conference (EDPC), 2015.

[5] S. Kato, N. Hoshi, K. Oguchi, "Small-scale hydropower", IEEE Industry Applications Magazine, vol. 9, no. 4, pp. 32 -38, July-Aug. 2003.

[6] M. Adamowicz, R. Strzelecki, "Cascaded doubly fed induction generator for mini and micro power plants connected to grid", in 13th Power Electronics and Motion Control Conference (EPE-PEMC), 2008.

[7] F. L. Neves, C. H. S. Vasconcelos, D. b. Lima, A. C. Ferreira, R. M. Stephan, "Steady State Operating Points of the Doubly Fed Cascaded Induction Machine", Eletrônica de Potência-SOBRAEP, vol. 17, no. 1, pp. 466-473, Fev 2012.

[8] C. H. S. de Vasconcelos, A. C. Ferreira, R. M. Stephan, "Wind turbine generator system based on Cascaded Doubly Fed Induction Generator", in IEEE 13th Brazilian Power Electronics Conference and 1st Southern Power Electronics Conference (COBEP/SPEC), pp. 1-6, 2015.

[9] B. Hopfensperger, D. J. Atkinson, R. A. Lakin, "Stator flux oriented control of a cascaded doubly-fed induction machine", IEE Proceedings - Electric Power Applications, vol. 146, no. 6, pp. 597 -605, Nov 1999.

[10] D. Basic, J. G. Zhu, G. Boardman, "Transient performance study of a brushless doubly fed twin stator induction generator", IEEE Transactions on Energy Conversion, vol. 18, no. 3, pp. 400-408, Sept 2003.

[11] S. Shao, E. Abdi, F. Barati, R. McMahon, "Stator-FluxOriented Vector Control for Brushless Doubly Fed Induction Generator", IEEE Transactions on Industrial Electronics, vol. 56, no. 10, pp. 4220-4228, Oct 2009.

[12] B. Hopfensperger, D. Atkinson, R. Lakin, "Combined magnetising flux oriented control of the cascaded doubly-fed induction machine", IEE Proceedings Electric Power Applications, vol. 148, no. 4, pp. 354 -362, Jul 2001.

[13] K. Ji, S. Huang, J. Zhu, Y. Gao, C. Zeng, "Vector control and synchronization of brushless doubly-fed machine for high power wind power generation", in 15th International Conference on Electrical Machines and Systems (ICEMS), 2012.

[14] M. Heydari, K. Smedley, "Comparison of maximum power point tracking methods for medium to high power wind energy systems", in 20th Conference on Electrical Power Distribution Networks Conference (EPDC), pp. 184-189, 2015.

[15] Q. Wang, L. Chang, "An intelligent maximum power extraction algorithm for inverter-based variable speed wind turbine systems", IEEE Transactions on Power Electronics, vol. 19, no. 5, pp. 1242-1249, 2004.

\section{BIOGRAPHIES}

Carlos Henrique Silva de Vasconcelos received the B.Sc. and M.Sc. degrees from the Pontifical Catholic University of Minas Gerais, Belo Horizonte, Brazil, in 2001 and 2006, respectively, and the D.Sc. degrees from Federal University of Rio de Janeiro (COPPE), in 2015, all in Electrical Engineering. His main interests are in the fields of control of electrical drives, power electronics, renewable energy and energy generation.

Antonio Carlos Ferreira received the B.Sc. and M.Sc. degrees from the Federal University of Rio de Janeiro, Rio de Janeiro, Brazil, in 1987 and 1991, respectively, and the $\mathrm{Ph} . \mathrm{D}$. degree from the University of Cambridge, Cambridge, U.K., in 1997, all in Electrical Engineering. Since 1989, he has been with the Graduate School of Engineering, Federal University of Rio de Janeiro, where he is currently an Associate Professor, teaching at both under-graduate and post-graduate levels. His main interests are power system and electrical machines.

Richard Magdalena Stephan received the B.Sc. degree in electrical engineering from the Instituto Militar de Engenharia (IME), Rio de Janeiro, in 1976, the M.Sc. degree in electrical engineering from the Federal University of Rio de Janeiro (UFRJ) in 1980, and the Dr.-Ing. degree in electrical engineering from Ruhr Universitat Bochum, Germany, in 1985. He has an MBA degree (2005) from the Center for Scientific Enterprise, London (CSEL), on Technology Enterprise Development. During 1977, he worked as an engineer at Furnas Centrais Elétricas, Rio de Janeiro. Since 1978, he has been with the Department of Electrical Engineering, UFRJ. He spent a sabbatical leave at CEPEL, the Research Center of ELETROBRAS in 1993. His main interests are in the fields of applications of superconductivity, control of electrical drives and power electronics. 